wonder there was not very much meaningful dialogue between them. The geophysicist became rooted (Narcissus-like) by the beauty of his mathematically elegant earth, and the geologist ceased to think about grand theories-a retreat from the standpoint of their nineteenth century predecessors.

Wegener's theory of continental drift can now be seen to have been the imaginative idea which has in time transformed the subject. (In the United States continental drift is still a phrase not used in polite society-it is called sea floor spreading).

Geophysicists have successively been converted (usually suddenly) to continental drift, each group in turn having previously vchemently argued that the theory was disproved by their own data. First to be converted were the palaeomagneticists, then came the heat flow experts, the isotope workers, the oceanographers, and now the geodesists. Soon, maybe, the seismologists will change their minds.

This new vision of the earth's interior goes a considerable way towards identifying convection currents in the earth's mantle as the cause of continental drift, the topography of the ocean floor and the major tectonic movements, both compressional and tensional, in the continents.

Professor Phillips's account provides a record for the non-mathematical reader of this long search for an adequate theory of the interior of the earth. He explains the simple physical ideas which were the basis of our knowledge; mechanics, elasticity, and heat conduction. He helps us to come to quantitative terms with the earth by calculations which only require simple arithmetic. I feel, however, that he lingers too long on the classical picture and he does not adequately convoy the excitement of the great changes which I have described. I think that, although he discusses continental drift and convection currents, he does not feel sufficiently at home with the new ideas to write entirely convincingly about them. He dismisses palaeomagnetism in one lukewarm paragraph and ignores the remarkable fit of South America and Africa and the most convincing of the geological evidence for drift-the Permo-Carboniferous glaciation (surely one of the greatest scientific discoveries of the nineteenth century).

Professor Phillips's book will be useful to many, and not least to students in British university geology departments, who will surely be soon requiring an understandable introduction to modern geophysics. S. K. RUNCons

\section{FAST REACTIONS}

\section{Fast Reactions and Primary Processes in Chemical Kinetics}

Edited by Stig Claesson. Pp. 487. (Interscience (Wiley): New York and London, 1967.) 2558.

THIs book is a collection of the papers presented at the Nobel symposium on "Fast Reactions and Primary Processes in Chemical Kinetics", organized by Professor Stig Claesson and held at Uppsala in August 1967. There is no apparent connexion between the Nobel symposia and the prizes, but the symmetrical dispositions in the group photograph of the winners of the 1967 awards, announced later in the year, is interesting.

The selection of participants for invited conferences such as this or the Solvay meetings, for example, is always, necessarily, a puzzle to those left out. The dictum, attributed to Cherwell, that the pleasure in receiving public honours was in seeing who was passed over, presumably applies to those invited here too. The feeling of exclusiveness is further engendered by Professor Porter's remarks on the nanosecond club (page 476).

The papers thomselves are largely reviews of the fields of the various authors with particular emphasis on their own work. Much of it will be familiar to workers in par- ticular areas but there is much to be gained from grouping together in a single volume, work with a variety of techniques on fields ranging from physical chemistry to biochemistry.

Techniques reviewed include flash photolysis by Norrish and by Porter, pulse radiolysis by Dainton, the temperature jump technique by Eigen, delayed fluorescence by Parker, the mixed flow method by Chance and the interesting new technique of flash optical rotatory dispersion by Strong and Richtol.

Two important techniques omitted are the shock tube and the discharge flow method which have yielded important information on elementary processes. A further general omission was a contribution on the physics of fast measurements dealing with the limitations on information obtainable from rapid measurements. Witt has provided this in part in discussing the variety of methods he has at his disposal in Berlin but a separate account would have been helpful.

At a review conference it is natural to look back, but many remarks mention lasers and molecular beams as if they were in the future rather than the present. Perhaps then the most important omission was those people working with nanosecond techniques now. The inclusion of $\mathrm{Dr}$ Kupperman may have remedied this, although his paper described his elegant steady state photolytic technique for producing high energy deuterium atoms.

As well as those mentioned already, there are also contributions by: Nikitin (energy transfer), Dainton (the chemistry of the electron), Eigen (proton transfer), Parker (triplet energy transfer), Weller (olectron transfer), and Chance (electron transfer in biological systems). There are also papers by Prigogine, Oosterhoff, Vinnik, E. M. Eyring, Pacault, Wettermark, H. Eyring, and Gutfreund. Although it is invidious to choose in such company, I found the reviews by Norrish, Dainton, Porter, Eigen and Chance most stimulating and useful.

Each paper is followed by one or two selceted questions and answers and the nature of these highlights the difference between a "review" meeting and a "current" meeting such as the discussions held by the Faraday Society. In these even the printed version gives the flavour of the real ideas and thoughts which are exchanged during the, usually, lively discussion. Here the questions tend to show only almost a general satisfaction.

The book was produced very rapidly after the meeting and is of a high standard. The editing as far as one can tell is good, although Witt's first paper on methods of measurement is so obviously taken from another book with its references to "chapters 4 to 8" (page 88) and "the following paper" (page 86).

Because of its price, the book may be of less use than it should be, particularly because as a "Conference Proceedings" it will be hard to catalogue, find and reference. It is part of the "Nobel" series, but as the previous volumes were all on biochemical topics this is not an obvious place for a chemist to look for a book on fast reactions. The book is an ideal case for an earlier suggestion (Nature, 216, $900 ; 1967)$ for a series, independent of individual publishers, of conference proceedings in physical chemistry, for example. As such it would be easily found and referenced by someone interested.

In short, I like the book but not the price. It should be in your library. Peter Borrell

\section{UNORTHODOX PHYSICS}

\section{Discovery in Physics}

By Leonard H. Greenberg. Pp. ix +239 . (Saunders: Philadelphia and London, 1968.) $40 s$.

Collections of experiments in elementary physics published in Britain tend towards a cookery-book style with assemblies of recipes which proceed linearly from the soup 